J. Reprod. Fert. (1966) 11, 245-255

\title{
EFFECT OF PROGESTERONE AND OESTRONE ON THE PRE-IMPLANTATION AND IMPLANTATION STAGES OF EMBRYO DEVELOPMENT IN THE RAT
}

\author{
JANE J. YASUKAWA AND ROLAND K. MEYER \\ University of Wisconsin, Department of Zoology, Madison, Wisconsin
}

(Received 14th Fuly 1965)

\begin{abstract}
Summary. A sequential study was made of non-delayed and of experimentally delayed rat blastocysts. Alterations in shape, axis lengths and area of non-delayed blastocysts first appeared on the afternoon of Day 5 of pregnancy. Similar changes were observed in delayed blastocysts beginning $12 \mathrm{hr}$ after the simultaneous administration of oestrone and progesterone. In both cases implantation occurred within the subsequent $24 \mathrm{hr}$. In contrast, delayed blastocysts maintained only with progesterone were markedly larger than normal but failed to demonstrate typical pre-implantation changes or to implant. Therefore it was concluded that changes necessary for and indicative of impending implantation are induced by the synergistic action of oestrone and progesterone on the blastocyst.

Blastocysts from non-delayed and delayed, oestrone-treated animals were consistently free of their zonae pellucidae at least $18 \mathrm{hr}$ prior to implantation $-6 \mathrm{hr}$ after pre-implantation changes were initially noted. Progesterone, although it appeared to influence zonae-loss during the period of delayed nidation, was ineffective in accelerating and synchronizing the shedding process unless associated with oestrone.
\end{abstract}

\section{INTRODUCTION}

Implantation in most mammals occurs a few days after the fertilized ovum enters the uterus; however, it is consistently and naturally retarded for varying periods of time in mammals such as the bear, roe deer, armadillo, seal, many of the Mustelids and Marsupials, and in the lactating, pregnant rat and mouse (Enders, 1963). During the period of delay the blastocyst lies free and dormant in the uterine lumen and resumes development only when conditions become favourable for implantation.

Studies by Cochrane \& Meyer (1957) from this laboratory and other investigators have shown that delayed nidation can be induced artificially in non-lactating rats by ovariectomy during early pregnancy and subsequent daily administrations of progesterone. Blastocysts of animals treated in this manner will implant only if oestrogen is administered simultaneously with progesterone. This finding suggests that oestrogen, when associated with progesterone, plays an important role in the induction of nidation in rats. 
It may induce implantation by acting on the blastocysts, on the uterus, or on both. It was of interest, therefore, to determine whether a sequential study of delayed blastocysts in castrated animals maintained on progesterone and treated with a single dose of oestrone would demonstrate subtle, but detectable, morphological changes prior to implantation. The terms 'implantation' and 'nidation' are used to indicate the stage at which a blastocyst becomes firmly attached to the endometrium as a result of trophoblastic invasion.

\section{MATERIALS AND METHODS}

Virgin female rats of the Holtzman strain, 90 to 110 days old, were maintained under constant conditions of illumination (lights on at 06.00 hours, off at 20.00 hours $)$ and temperature $\left(26 \pm 1^{\circ} \mathrm{G}\right.$ ). Females in pro-oestrus were caged overnight with fertile males and checked for evidence of insemination between 08.00 hours and 10.00 hours the following morning. The day that spermatozoa were found in the vaginal smears was designated as Day 1 of pregnancy.

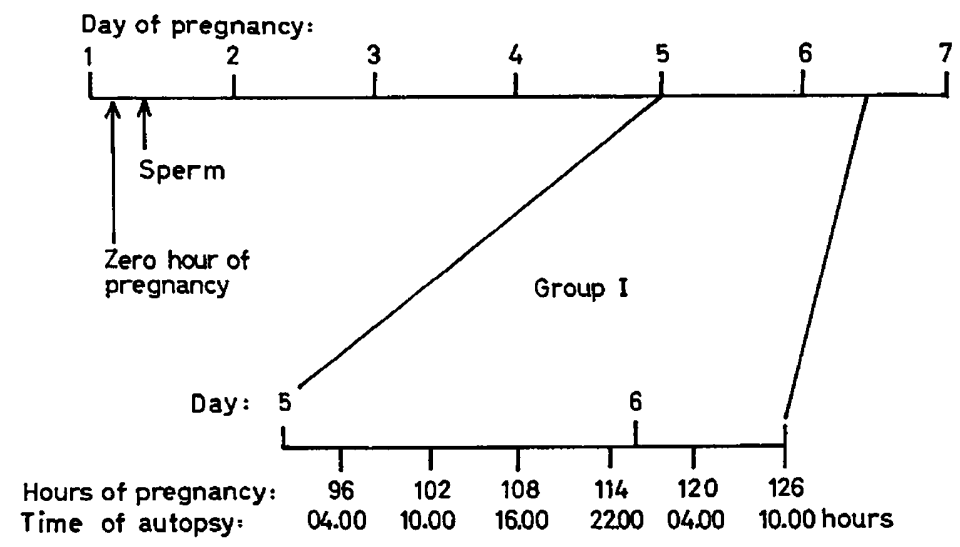

TEXT-FIG. 1. Experimental design for intact rats. Each day begins at midnight (Central Standard Time).

Group I (control) consisted of six subgroups of intact, untreated, pregnant animals. Animals from each subgroup were killed, two at a time, at 6-hr intervals beginning $96 \mathrm{hr}$ after the estimated time of fertilization (refer to Text-fig. 1). On the basis of the findings of Everett, Sawyer \& Markee (1949) and Austin \& Braden (1954), we calculated that animals on our schedule of illumination ovulate between 02.00 hours and 03.30 hours during the morning following the day of pro-oestrus. Since more than $50 \%$ of the ova are fertilized within $2 \mathrm{hr}$ of ovulation (Odor \& Blandau, 1951), 04.00 hours on the morning after pro-oestrus was considered to be the time of fertilization for all ova examined. Our estimated time of fertilization was in agreement with the findings of Szollosi \& Ris (1961), who worked with Holtzman rats maintained under similar conditions.

Groups II and III consisted of pregnant rats in which artificial delay of nidation was induced by the method described by Cochrane et al. (1957). Surgical procedures were conducted under ether anaesthesia and semisterile 
conditions. Hormones were administered subcutaneously in $0.25 \mathrm{ml}$ of corn oil. The experimental design is shown in Text-fig. 2. Ovariectomy was performed on Day 3 of pregnancy ( 50 to $56 \mathrm{hr}$ after spermatozoa were found) and followed by daily injections of $4 \mathrm{mg}$ of progesterone to Day 8 . On the morning of Day 9 , unless implantation sites were visible at laparotomy, the animals were allotted to two groups and given a final steroid injection at 10.00 hours as follows: Group II received $4 \mathrm{mg}$ of progesterone and Group III received $1 \mu \mathrm{g}$ of oestrone in conjunction with $4 \mathrm{mg}$ of progesterone. Animals in these two groups were assigned to subgroups which were killed at 6-hr intervals beginning at the time of the last injection. This part of the experiment was designed so that each subgroup of a group corresponded to a subgroup of the other. One animal from a subgroup of Group II and another from a corresponding subgroup of Group

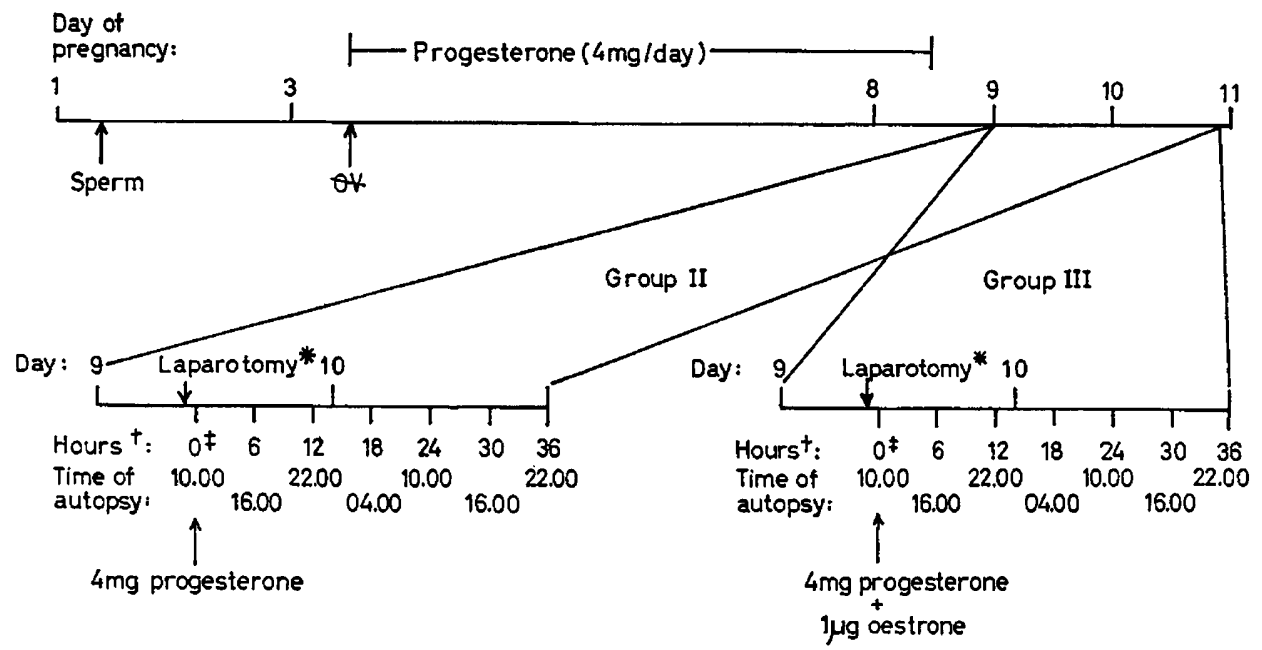

TEXT-FIG. 2. Experimental design for treated rats. Each day begins at midnight (Central Standard Time).

* Uterus grossly examined for implantation sites. If no sites are evident the final injection of steroid(s) is administered at zero hour.

$\dagger$ Number of hours after the final steroid(s) administration.

\$ Subgroup sacrificed at the time when the final steroid(s) should have been administered.

III were usually killed simultaneously. Animals autopsied at zero hour received no steroid treatment on Day 9 so that blastocysts exemplifying the state of the embryos at the time of the final steroid injection could be recovered and observed.

At the time of killing the anaesthetized animal was bled to reduce the amount of blood in the uterus, and then exposed to an overdose of ether. The uterine horns were exposed by a mid-ventral incision, excised and separated at the cervical region. The left horn was prepared for histological studies and the right horn was flushed with tepid Eagle's Basal Medium ( $\mathrm{pH} 7.2$ to 7.4) to obtain live blastocysts. The fluid was collected in a large depression slide and, with the aid of a binocular dissecting microscope, the blastocysts were located, grouped, drawn into a micropipette and transferred to the centre of a small depression slide. Whenever possible each blastocyst was positioned so that the inner cell mass was visible. They were photographed with a Zeiss Photomicroscope under 
phase-contrast and under ordinary light. All procedures were performed rapidly to minimize changes in the blastocysts. The experiment was repeated to obtain a sufficient number of blastocysts. The numbers of animals used and blastocysts observed in this study are given in Table 1 .

TABLE 1

ZONAE-ENCASED BLASTOCYSTS RECOVERED FROM THE RIGHT UTERINE HORNS OF INTAGT AND TREATED RATS

\begin{tabular}{|c|c|c|c|c|}
\hline $\begin{array}{l}\text { Treatment } \\
\text { group }\end{array}$ & $\begin{array}{c}\text { Total } \\
\text { animals }\end{array}$ & $\begin{array}{c}\text { Animals } \\
\text { having } \\
\text { blastocysts } \\
\text { with zonae }\end{array}$ & $\begin{array}{c}\text { Blastocysts } \\
\text { with zonael } \\
\text { Total No. }\end{array}$ & Blastocysts with zonae per rat/Examined per rat \\
\hline $\begin{array}{l}\text { I. Intact } \\
96 \mathrm{hr} \\
102 \mathrm{hr} \\
108 \mathrm{hr} \\
114 \mathrm{hr} \\
120 \mathrm{hr} \\
126 \mathrm{hr}\end{array}$ & $\begin{array}{r}4 \\
7 \\
4 \\
10 \\
7 \\
7\end{array}$ & $\begin{array}{l}4 \\
7 \\
2 \\
0 \\
0 \\
0\end{array}$ & $\begin{array}{r}11 / 11 \\
30 / 30 \\
3 / 14 \\
0 / 23 \\
0 / 15 \\
0 / 13\end{array}$ & $\begin{array}{l}6 / 6 ; 1 / 1 ; 2 / 2 ; 2 / 2 \\
4 / 4 ; 4 / 4 ; 2 / 2 ; 7 / 7 ; 6 / 6 ; 1 / 1 ; 6 / 6 \\
2 / 2 ; 1 / 4 ; 0 / 4 ; 0 / 4 \\
0 / 4 ; 0 / 4 ; 0 / 2 ; 0 / 1 ; 0 / 1 ; 0 / 3 ; 0 / 1 ; 0 / 2 ; 0 / 3 ; 0 / 2 \\
0 / 2 ; 0 / 2 ; 0 / 2 ; 0 / 3 ; 0 / 1 ; 0 / 1 ; 0 / 4 \\
0 / 1 ; 0 / 1 ; 0 / 2 ; 0 / 4 ; 0 / 2 ; 0 / 1 ; 0 / 2\end{array}$ \\
\hline $\begin{array}{l}\text { II. Progesterone } \\
0 \mathrm{hr} \dagger \\
6 \mathrm{hr} \ddagger \\
12 \mathrm{hr} \\
18 \mathrm{hr} \\
24 \mathrm{hr} \\
30 \mathrm{hr}\end{array}$ & $\begin{array}{l}4 \\
5 \\
6 \\
5 \\
6 \\
5\end{array}$ & $\begin{array}{l}1 \\
0 \\
2 \\
2 \\
5 \\
2\end{array}$ & $\begin{array}{l}1 / 13 \\
0 / 9 \\
3 / 10 \\
4 / 15 \\
6 / 14 \\
4 / 18\end{array}$ & $\begin{array}{l}1 / 1 ; 0 / 2 ; 0 / 2 ; 0 / 8 \\
0 / 2 ; 0 / 2 ; 0 / 1 ; 0 / 3 ; 0 / 1 \\
2 / 2 ; 1 / 2 ; 0 / 2 ; 0 / 2 ; 0 / 1 ; 0 / 1 \\
1 / 3 ; 3 / 3 ; 0 / 3 ; 0 / 5 ; 0 / 1 \\
1 / 1 ; 1 / 1 ; 1 / 3 ; 1 / 1 ; 2 / 3 ; 0 / 5 \\
2 / 4 ; 2 / 6 ; 0 / 3 ; 0 / 3 ; 0 / 2\end{array}$ \\
\hline $\begin{array}{l}\text { III. Oestrone + } \\
\text { progesterone } \\
0 \mathrm{hr} \dagger \\
6 \mathrm{hr} \ddagger \\
12 \mathrm{hr} \\
18 \mathrm{hr} \\
24 \mathrm{hr} \\
30 \mathrm{hr}\end{array}$ & $\begin{array}{l}4 \\
5 \\
8 \\
6 \\
7 \\
8\end{array}$ & $\begin{array}{l}1 \\
2 \\
2 \\
0 \\
0 \\
0\end{array}$ & $\begin{array}{l}1 / 13 \\
6 / 19 \\
3 / 23 \\
0 / 15 \\
0 / 14 \\
0 / 20\end{array}$ & $\begin{array}{l}1 / 1 ; 0 / 2 ; 0 / 2 ; 0 / 8 \\
2 / 4 ; 4 / 6 ; 0 / 4 ; 0 / 1 ; 0 / 4 \\
2 / 3 ; 1 / 3 ; 0 / 2 ; 0 / 6 ; 0 / 1 ; 0 / 3 ; 0 / 1 ; 0 / 4 \\
0 / 5 ; 0 / 2 ; 0 / 2 ; 0 / 4 ; 0 / 1 ; 0 / 1 \\
0 / 2 ; 0 / 2 ; 0 / 1 ; 0 / 1 ; 0 / 5 ; 0 / 1 ; 0 / 2 \\
0 / 1 ; 0 / 2 ; 0 / 5 ; 0 / 3 ; 0 / 1 ; 0 / 4 ; 0 / 3 ; 0 / 1\end{array}$ \\
\hline
\end{tabular}

Total number of blastocysts actually recovered exceeds the total number recorded in this Table because those which did not meet the criteria set at the beginning of the experiment were eliminated.

* Subgrouped according to age of blastocysts as calculated from the estimated time of fertilization.

† Blastocysts collected at the time when the final steroid(s) should have been administered. Zero hour subgroups of Groups II and III are the same.

¥ Subgrouped according to number of hours after the final steroid(s) administration.

It was apparent that the lengths of the major and minor axes of blastocysts may vary, depending on their position and the surface photographed. Therefore blastocysts were always photographed at the level of their greatest diameter, and their axis lengths (excluding the zonae pellucidae) determined from photographs only if the inner cell mass was visible. The major axis of the blastocyst was an imaginary line which bisected the inner cell mass; the minor axis was determined to be the greatest diameter and perpendicular to the major axis. Any blastocyst whose length exceeded its width by more than $10 \mu$ was considered an ellipse and its area computed by the formula:

$$
\text { Area of ellipse }=\pi(a / 2)(b / 2)
$$

where $a$ and $b$ are lengths of the major and minor axes respectively. On the other hand, any blastocyst whose length was within $10 \mu$ of its width was considered a circle and its area calculated by the formula: 


$$
\text { Area of circle }=\pi R^{2}
$$

where $R$ is the radius (the diameter was considered as the average of the lengths of the two axes).

The ratio between the major and minor axis lengths was determined and used as an indication of the shape of the blastocyst. The axis ratios of those blastocysts considered to be circular never exceeded $1 \cdot 17: 1$.

Statistical analyses were performed for studies of areas, axis lengths and axis ratios of the blastocysts. A simultaneous significance test for unequal replication -Duncan's (1955) multiple range test-was also conducted to compare the area of each treatment mean with that of every other treatment mean.

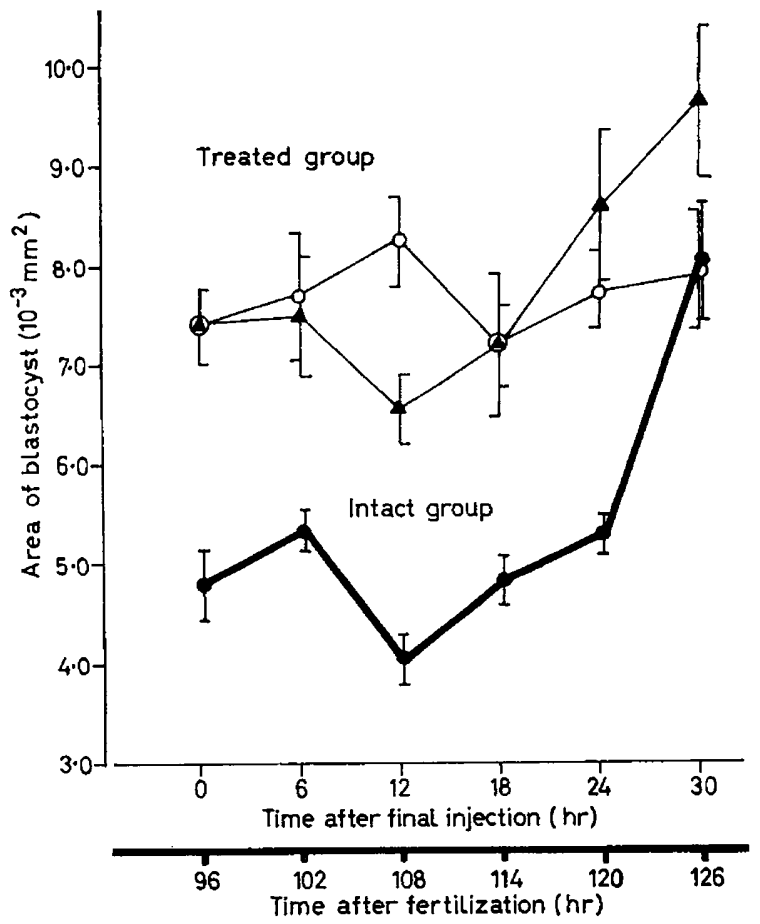

TEXT-FIG. 3. Changes in area $\left(10^{-3} \mathrm{~mm}^{2}\right)$ of rat blastocysts. Intact animals; $O$, progesterone-treated animals; $\boldsymbol{\Lambda}$, oestrone+ progesterone-treated animals; S.E. calculated.

Blastocysts recovered from animals in Group I at $126 \mathrm{hr}$ after fertilization and those recovered from Group III at $30 \mathrm{hr}$ after the oestrone-progesterone treatment were considered to be at equivalent stages of development since, in both cases, preliminary studies showed that blastocysts could no longer be flushed from the uterus during the subsequent $6-\mathrm{hr}$ interval. Therefore all three treatment groups were compared by placing the data from the last autopsy interval to the far right of the graph and at the same point on the horizontal $(X)$ axis (Text-figs. 3 to 5). Data from preceding subgroups of each type of treatment were then aligned in regressing order.

The presence or absence of zonae pellucidae was noted by direct observation of live blastocysts and was confirmed by examination of their photographs. 


\section{RESULTS}

The results of this investigation are summarized in Table 1 and in Text-figs. 3 to 5. Photographs of blastocysts are included in Plates 1 and 2.

Pre-implantation changes observed in blastocysts from intact, untreated rats (P1. 1, Figs. 1 to 3)

As shown in Text-fig. 3, the area of the blastocyst remained unaltered during the first two intervals of observation. However, by $108 \mathrm{hr}$ a reduction in area, significantly different $(P<0.05)$ as compared to that at $102 \mathrm{hr}$, was noted.

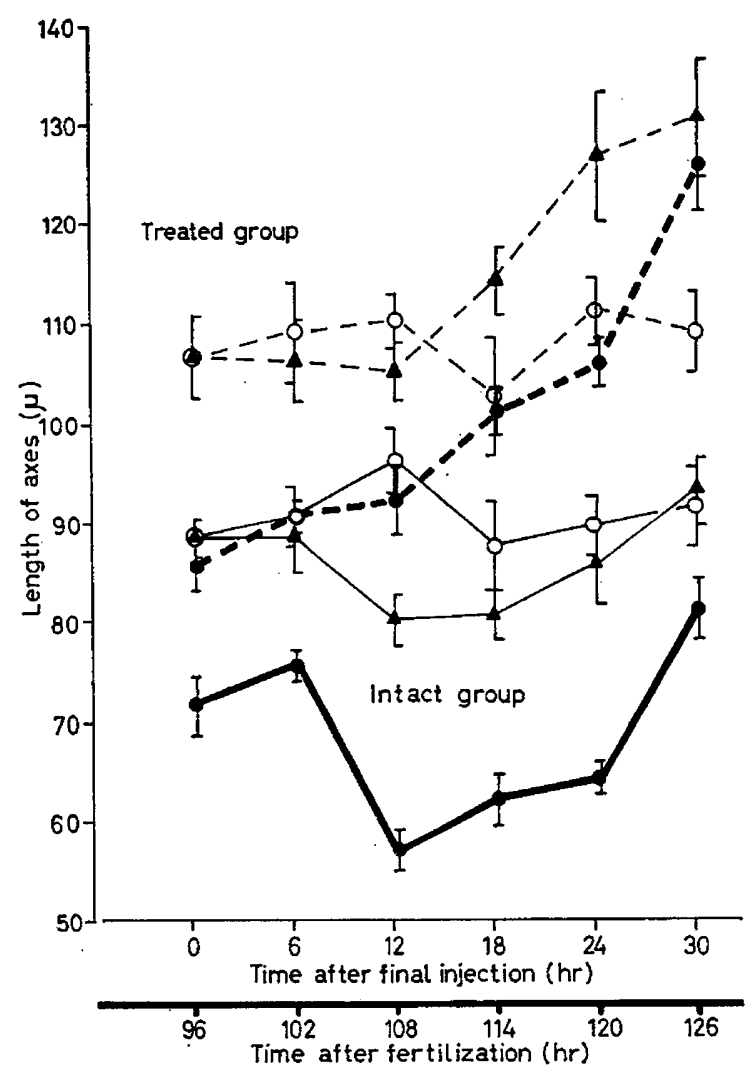

TExT-FIG. 4. Changes in major ( . . - ) and minor ( - ) axis lengths of rat blastocysts. - Intact animals; $O$, progesterone-treated animals; $\Delta$, oestrone + progesterone-treated animals; S.E. calculated.

Increases in area were slight during the ensuing 12-hr interval; then by $126 \mathrm{hr}$ a rapid increase occurred such that the blastocyst was at least 1.5 times its original area and significantly larger $(P<0.01)$ than any of the others. Histological sections of 132-hr blastocysts in utero confirmed that trophoblastic penetration of the maternal endometrium was already well established (Pl. 2, Figs. 8 and 9).

The observed changes in area of pre-implantation blastocysts were associated 
with changes in minor and/or major axis lengths (Text-fig. 4) and in configuration (Text-fig. 5). When the blastocyst area was at its minimum at $108 \mathrm{hr}$ only the minor axis length (width) was markedly reduced. This phenomenon was reflected in the sudden increase in axis ratio and transformation of the blastocyst from a circular to an elliptical structure. In contrast, blastocyst enlargement which followed corresponded with increases in both axis lengths (although, of the two, the major axis appeared to lengthen at a faster rate) thereby maintaining the elliptical configuration until implantation occurred.

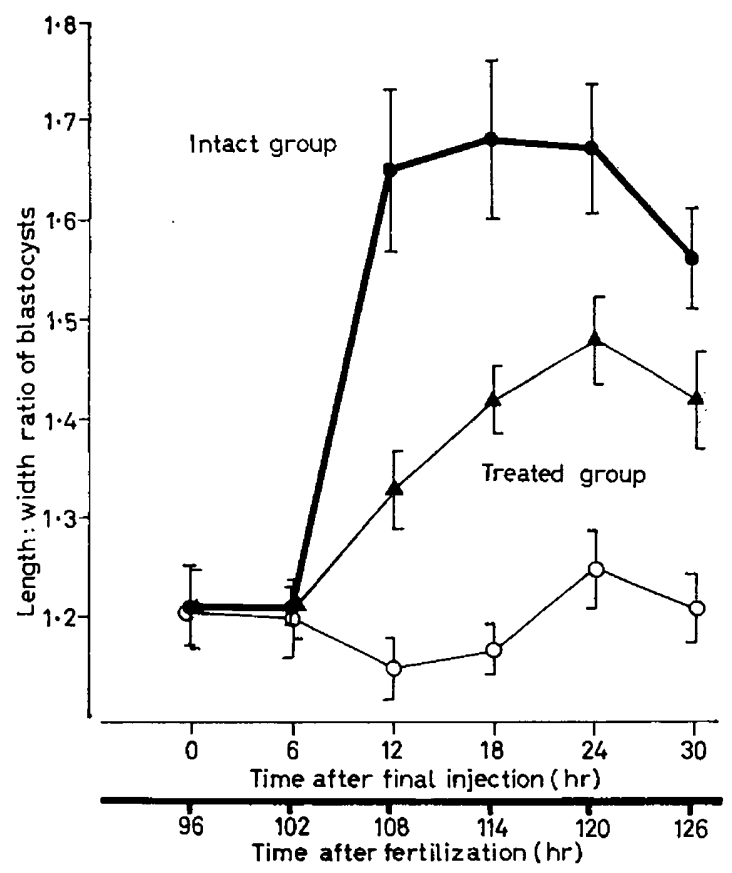

TEXT-FIG. 5. Changes in axis ratios of rat blastocysts. Intact animals; $O$, progesteronetreated animals; $\boldsymbol{\Delta}$, oestrone + progesterone-treated animals; S.E. calculated.

The data shown in Table 1 indicate that loss of the zonae pellucidae by blastocysts commenced at some time between 102 and $108 \mathrm{hr}$. By $108 \mathrm{hr}$ only $29 \%$ of the recovered blastocysts were zonae-encased and by $114 \mathrm{hr}$ (up to $18 \mathrm{hr}$ before the time of implantation) all of them were zonae-free.

Effect of progesterone on delayed blastocysts (Pl. 1, Figs. 4 and 5)

Throughout the $30-\mathrm{hr}$ period of observation, progesterone-delayed blastocysts did not demonstrate pre-implantation changes in area, shape and axis lengths. They were, however, markedly larger in area $(P<0.01)$ than non-delayed blastocysts, except when the latter attained their maximally expanded condition at $126 \mathrm{hr}$ (Text-fig. 3). This enlarged condition was consistently reflected in the increased lengths of the major and minor axes as contrasted with those of blastocysts from intact animals (Text-fig. 4). Blastocysts from animals in this group were always circular in shape (Text-fig. 5). 
Some of the blastocysts from animals in this group retained their zonae. Table 1 shows that in all of the subgroups the numbers of zonae-encased blastocysts recovered varied regardless of the interval after the final injection of progesterone.

\section{Effect of oestrone and progesterone on delayed blastocysts (Pl. 1, Figs. 5 to 7)}

Blastocysts recovered from animals at zero and $6 \mathrm{hr}$ after the administration of oestrone and progesterone were indistinguishable from each other and from those of progesterone-treated animals (Text-fig. 3). However, $12 \mathrm{hr}$ after oestrone and progesterone were administered to the animal the blastocyst was significantly smaller $(P<0.05)$ than those from 12 - and 30 -hr progesteronetreated animals. During subsequent intervals the blastocyst area gradually increased until by the 24th $\mathrm{hr}$ it was significantly greater $(P<0.01)$ than at $12 \mathrm{hr}$. The maximum area was attained at $30 \mathrm{hr}$. After $36 \mathrm{hr}$ of oestroneprogesterone treatment trophoblastic invasion of the maternal endometrium was apparent in histological sections of blastocysts in utero (Pl. 2, Figs. 10 and 11).

The decrease in area noted at the 12-hr interval was reflected in the blastocyst as a decrease in the minor axis length (Text-fig. 4) and the assumption of an elliptical configuration (Text-fig. 5). Increases in area that occurred subsequently, however, seemed to be primarily associated with increases in the major axis lengths. This change was correlated with the trend toward continued elongation such that blastocysts became more elliptical in shape up to the time of implantation.

Some of the blastocysts had zonae if recovered during the first $12 \mathrm{hr}$ after oestrone-progesterone treatment was begun (Table 1). On the other hand, blastocysts under the influence of both hormones for $18 \mathrm{hr}$ or more were consistently zonae-free.

\section{EXPLANATION OF PLATE 1}

Figs. 1 to 3. Ordinary light photomicrographs of typical blastocysts recovered from intact rats. $\times 390$.

Fic. $1.96 \mathrm{hr}$ after fertilization. The zona-encased ovum is circular and consists of a welldeveloped blastocoele and of large cells.

FIG. 2. $108 \mathrm{hr}$ after fertilization. It appears as though an increase in cell numbers, a decrease in cell volume and blastocoele size, and a change in shape occurred.

FIG. 3. $126 \mathrm{hr}$ after fertilization. The elliptical ovum is markedly expanded as is its blastocoele in comparison with those recovered at earlier stages. Cellular compression is noticeable and may be the result of an increase in fluid within the blastocoele.

Fig. 4. Ordinary light photomicrograph of a blastocyst typical of those recovered from progesterone-treated delayed rats on the 9 th or 10 th day of pregnancy, $30 \mathrm{hr}$ after the final progesterone administration. The large, zona-free blastocyst is circular and has an enlarged blastocoele. $\times 390$.

Fics. 5 to 7. Phase-contrast photomicrographs of typical blastocysts recovered from oestrone + progesterone-treated rats on the 9 th and 10th day of pregnancy. $\times 390$.

FIG. 5. Zero hr. The blastocyst is similar in appearance to that shown in Fig. 4. Note that this ovum is losing its zona; the abembryonic pole is first to be denuded.

FIG. $6.12 \mathrm{hr}$ after treatment. This zona-free blastocyst is slightly more elliptical in shape than those shown in Figs. 4 and 5 but still bears a marked resemblance to the latter.

Fig. $7.30 \mathrm{hr}$ after treatment. This blastocyst was the largest seen during this study. It is definitely more elliptical in shape than those recovered from treated animals at earlier stages. A protuberance, suggestive of an implantation cone, is apparent on the lower left of the photomicrograph. 
PLATE 1

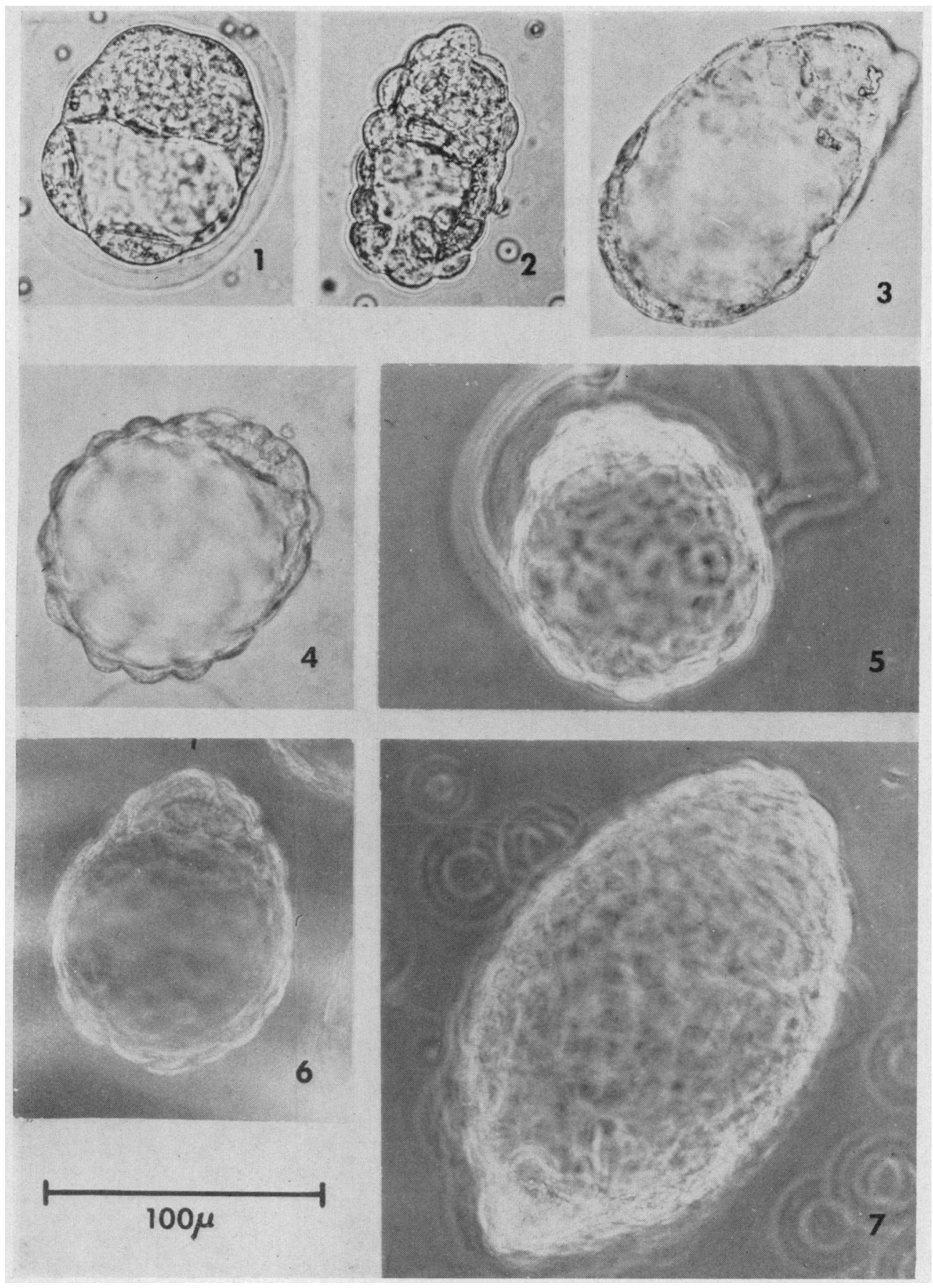

(Facing p. 252) 


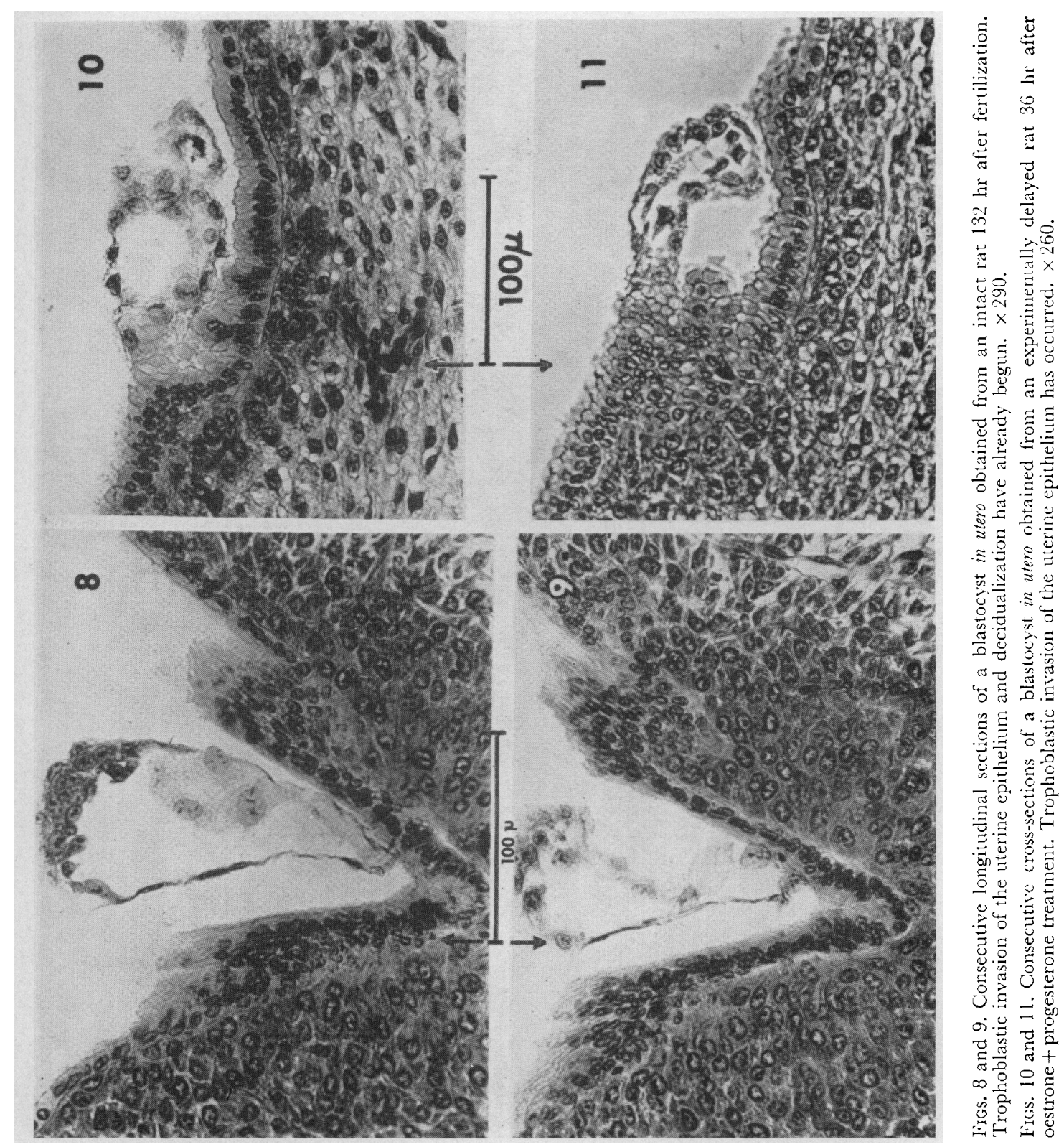




\section{DISCUSSION}

\section{Changes in area, shape and axis lengths}

Blastocysts from intact rats, studied sequentially, demonstrate detectable morphological changes before implantation. At a precise stage of development, $108 \mathrm{hr}$ after fertilization, the blastocyst undergoes a statistically significant decrease in area and a decrease in width, and is transformed from a circular to an elliptical structure. During the subsequent $24 \mathrm{hr}$, although no further alteration in configuration is observable, lengthening of both axes and expansion occur until invasion of the maternal endometrium (implantation) is accomplished by $132 \mathrm{hr}$ after fertilization.

Delayed blastocysts from pregnant, ovariectomized, progesterone-treated animals demonstrate similar pre-implantation changes under the proper hormonal conditions. When oestrone and progesterone are simultaneously administered to the test animal on Day 9 of pregnancy the delayed blastocyst begins to undergo morphological changes within $12 \mathrm{hr}$ and continues to alter its appearance until it implants $24 \mathrm{hr}$ later. This sequence of events occurs only in the presence of oestrone in conjunction with progesterone at intervals before implantation that are comparable to that of non-delayed blastocysts. These findings indicate that, in rat blastocysts, morphological changes associated with implantation are not progesterone dependent, but are induced, either directly or indirectly, by the synergistic action of oestrone and progesterone. The data presented can also be interpreted as evidence supporting Shelesnyak's theory of the occurrence of an oestrogen surge during early pregnancy. On the basis of this study, it seems feasible to postulate that the effective level of circulating ovarian oestrogen is reached at the beginning of Day 5 of pregnancy, 30 to $36 \mathrm{hr}$ before the time of implantation, rather than during the latter half of the 4th day after insemination as proposed by Shelesnyak, Kraicer \& Zeilmaker (1963).

That expansion of rat blastocysts occurs within the first 9 days of delay, while they are maintained under the influence of progesterone, is clearly shown in this study. However, other than causing increases in area and in axis lengths, this growth has no effect on the axis ratios and shape of the blastocysts. Perhaps the relationship between progesterone and blastocyst expansion, which Blandau (1961) indicates is limited to the leporid family of rodents, also exists in the rat. He states: "A plausible explanation is that the expansion may be due simply to the processes of osmosis, the changes in size being related to ionic variations of the fluid within the blastocyst cavity and the surrounding environment".

Since a decrease in blastocyst area is due to the shortening of only one axis rather than to shrinkage, it probably is not caused entirely by movement of fluid between the blastocoele and the uterine lumen. It seems that the embryonic cells play an active role here as a result of the direct or indirect influence of oestrone and progesterone.

\section{Zonae pellucidae}

Our results demonstrate that some delayed blastocysts from progesteronetreated animals retain their zonae 9 and 10 days after fertilization. This suggests that loss of the zona is not dependent on the age of the blastocysts and is 
accomplished at random. Since they are markedly expanded as compared to normal blastocysts, it is possible that, in some, sufficient pressure is exerted against the zona to cause it to rupture. It was of interest that two blastocysts from this group were observed while shedding their zonae. They appear to free themselves of their zonae when the latter breaks at the abembryonic pole (Pl. 1, Fig. 5). This implies that this pole is an intrinsic area of weakness and thus most apt to rupture when a force is applied.

Non-delayed blastocysts lose their zonae pellucidae late in Day 5 of pregnancy-some at $108 \mathrm{hr}$ and all by $114 \mathrm{hr}$ of age. These findings substantiate those of Dickmann \& Noyes (1961) who established 20.00 hours on Day 5 of pregnancy ( $112 \mathrm{hr}$ after our estimated time of fertilization) as the time when all blastocysts from intact rats are zonae-free. On the other hand, delayed blastocysts from oestrone-progesterone animals are no different from those of progesterone-treated rats until the 18-hr interval. At this time, approximately $18 \mathrm{hr}$ before implantation, all of the blastocysts are consistently zonae-free. This suggests that in the presence of oestrone and progesterone for 6 or $12 \mathrm{hr}$ the zona may still be shed in a random manner similar to that of the progesterone-influenced blastocyst. Since blastocysts are all free of their zonae at comparable times (about $18 \mathrm{hr}$ ) before implanting, it seems that the presence of oestrone, in conjunction with progesterone, is necessary for synchronization and acceleration of the shedding process.

It is notable that the time of shedding of the zonae by blastocysts from both groups of animals is closely associated with the time of the appearance of the morphological changes. All of these blastocysts are free of their zonae $6 \mathrm{hr}$ after the areas and the minor axis lengths decrease and they become elliptical in shape. Therefore, consistent loss of the zonae cannot be attributed to pressure, but must be due to another factor. This factor is, apparently, also dependent on the synergistic action of oestrone and progesterone, as are the morphological changes. Perhaps a lytic agent is released by the trophoblast when it reaches a certain stage of development as proposed by Dickmann et al. (1961). In which case, the morphological alterations may be indicative of changes in properties and functions of the embryonic cells which synthesize and/or release the substance. This seems feasible since zona loss follows the appearance of preimplantation changes.

\section{ACKNOWLEDGMENTS}

This study was supported in part by Grant 86-4250, National Institutes of Health and by The Ford Foundation.

\section{REFERENCES}

Austin, G. R. \& Braden, A. W. H. (1954) Time relations and their significance in the ovulation and penetration of eggs in rats and rabbits. Aust. 7. biol. Sci. 7, 179.

BLANDAu, R. J. (1961) Biology of eggs and implantation. Sex and Internal Secretions, 3rd edn, p. 859. Ed. W. C. Young. Williams \& Wilkins, Baltimore.

Cochrane, R. L. \& Meyer, R. K. (1957) Delayed nidation in the rat induced by progesterone. Proc. Soc. exp. Biol. Med. 96, 155.

Dickmann, Z. \& Noyes, R. W. (1961) The zona pellucida at the time of implantation. Fert. Steril. 12, 310. 
Duncan, D. B. (1955) Multiple range and multiple $F$-test. Biometrics, 11, 1.

Enders, A. C. (1963) Delayed implantation. University of Chicago Press.

Everett, J. W., SAWYer, C. H. \& Markee, J. E. (1949) A neurogenic timing factor in control of the ovulatory discharge of luteinizing hormone in the cycling rat. Endocrinology, 44, 235.

OdOR, D. L. \& BLANDAU, R. J. (1951) Observations on fertilization and the first segmentation division in rat ova. Am. 7. Anat. 89, 29.

Shelesnyak, M. C., Kraicer, P. F. \& Zeilmaker, G. H. (1963) Studies on the mechanism of decidualization. I. The oestrogen surge of pseudopregnancy and progravidity and its role in the process of decidualization. Acta endocr., Copenh. 42, 225.

Szollosi, D. G. \& Ris, H. (1961) Observations on sperm penetration in the rat. F. biophys. biochem. Cytol. 10, 275. 